S. Wellens, B. Thijs, C. Möller, K. Binnemans

Physical Chemistry Chemical Physics 15, 9663-9669 (2013)

\title{
Separation of Cobalt and Nickel by Solvent Extraction with Two Mutually Immiscible Ionic liquids
}

\author{
Sil Wellens, ${ }^{a}$ Ben Thijs, ${ }^{b}$ Claudia Möller ${ }^{b}$ and Koen Binnemans ${ }^{* a}$ \\ Received (in $X X X, X X X) X$ th $X X X X X X X X X 20 X X$, Accepted Xth $X X X X X X X X X 20 X X$ \\ ${ }_{5}$ DOI: 10.1039/b000000x
}

The proof-of-principle for the separation of metals by solvent extraction using two mutually immiscible ionic liquids is given. Cobalt was extracted from the ionic liquid 1-ethyl-3-methylimidazolium chloride to the ionic liquid trihexyl(tetradecyl)phosphonium bis-(2,4,4-trimethylpentyl)phosphinate. A distribution ratio of 44 was obtained. Cobalt could be selectively separated from nickel, with a separation factor of 10 205. The extraction mechanism was elucidated using UV-VIS absorption measurements. The mutual solubility between the two ionic liquids was determined by ${ }^{1} \mathrm{H}$ NMR. Processing steps such as washing, stripping and regeneration of the ionic liquid phases are discussed.

\section{Introduction}

Solvent extraction (SX) is one of the most important 15 hydrometallurgical processes in the refining of metals, especially of precious metals, rare earths and cobalt-nickel, by separation and purification. ${ }^{1}$ Solvent extraction is based on the preferential distribution of the dissolved metal ions between two mutually immiscible phases, in general an aqueous phase and an organic ${ }_{20}$ phase. Transfer of the metal ion from one phase to the other is enabled by an extracting agent (extractant). During the last decade, considerable research efforts have been devoted to the replacement of the organic phase in solvent extraction systems by an ionic liquid. ${ }^{2-9}$ Ionic liquids are solvents entirely consisting of 25 ions. ${ }^{10-12}$ They have a negligible vapour pressure, so that they are non-volatile and have a very high flash point. Substitution of the volatile hydrocarbon-based organics by ionic liquids could lead to inherently safer and environmentally friendlier extraction processes. So far, most studies on the application of ionic liquids 30 in solvent extraction processes have made use of ionic liquids with fluorinated anions, e.g. hexafluorophosphate or bis(trifluoromethylsulfonyl)imide anions, because these ionic liquids are highly hydrophobic and hence immiscible with water. Unfortunately, fluorine-containing ionic liquids are expensive 35 and there are issues with their stability (e.g. hydrolysis of hexafluorophosphate ions) and persistency in nature. There are few examples of solvent extraction studies with non-fluorinated ionic liquids, most of them make use of an organic solvent as diluent. ${ }^{13-16}$ Recently, we developed a very efficient solvent 40 extraction process for the separation of cobalt and nickel from chloride solutions based on the undiluted ionic liquid trihexyl(tetradecyl)phosphonium chloride as organic phase. ${ }^{17}$

In this paper, we give the proof-of-principle for the separation of metal ions by distribution between two mutually immiscible 45 ionic liquids. The example of separation of cobalt and nickel is discussed. Substitution of the aqueous phase by an ionic liquid phase in a solvent extraction process has several advantages. First of all, the extraction mechanism can be different, offering the possibility to change the distribution ratios and to improve the 50 separation factors. Secondly, the more polar ionic liquid can be used as a leaching solution to dissolve metal oxides and metal salts. ${ }^{18,19}$ This allows leaching at elevated temperatures, without the need of using autoclaves. More selective leaching is possible as well. ${ }^{20,21}$ Mutually immiscible ionic liquids have been ${ }_{55}$ reported, ${ }^{22-24}$ but their use in separation processes has been restricted to the extraction of organic compounds. ${ }^{26}$ There exist some examples of extraction systems containing an inorganic molten salt and an organic phase ${ }^{26-28}$ but none for the metal distribution between two mutually immiscible ionic liquids.

\section{${ }_{60}$ Experimental}

\section{Chemicals}

Trihexyl(tetradecyl)phosphonium

bis $(2,4,4-$ trimethylpentylphosphinate) (Cyphos ${ }^{\circledR}$ IL 104, > 97\%) and 1ethyl-3-methylimidazolium chloride $(>98 \%)$ were purchased 65 from Iolitec (Heilbronn, Germany). $\mathrm{CoCl}_{2}$ (>97\%), $\mathrm{NiCl}_{2}$ (>98\%), sulfuric acid (95-97\%) were purchased from Sigma Aldrich. Dioxane (stabilized, $99.5 \%$ ) was purchased from Acros Organics (Geel). Ammonia (Analar Normapur, min. 25 w.\%) was purchased from VWR. All chemicals were used as received, 70 without further purification.

\section{Instrumentation and analysis methods}

A Mettler Toledo DL 39 Karl Fischer Coulometer was used for determination of the water content in ionic liquids. To quantify the metal content, a benchtop total reflection X-ray fluorescence 75 (TXRF) spectrometer (Picofox S2, Bruker) was used. For quantification of the metal in $\left[\mathrm{P}_{66614}\right]\left[\mathrm{R}_{2} \mathrm{POO}\right]$ and $\left[\mathrm{C}_{2} \mathrm{mim}\right] \mathrm{Cl}$, 
about $0.2 \mathrm{~g}$ of the ionic liquid solution was diluted in dioxane and water $(20 \mathrm{~mL})$ respectively. Then a gallium solution (in $\mathrm{HNO}_{3}$ ) was added as an internal standard to the solution. An aliquot of $10 \mu \mathrm{L}$ of solution was put on a quartz glass carrier, dried in a hot5 air-oven at $60{ }^{\circ} \mathrm{C}$, then measured with a measurement time of 400 s. A Heraeus Megafuge 1.0 centrifuge was used for centrifugation of the samples after extraction. ${ }^{1} \mathrm{H}$ NMR spectra were recorded on a Bruker Avance 300 spectrometer, operating at $300 \mathrm{MHz}$ for ${ }^{1} \mathrm{H}$. The samples were dissolved in deuterated chloroform and the 10 chemical shifts are given in ppm relative to tetramethylsilane (TMS). ${ }^{31} \mathrm{P}$ NMR spectra were recorded on a Bruker Avance 400 spectrometer, operating at $161.98 \mathrm{MHz}$ for ${ }^{31} \mathrm{P}$. The samples were dissolved in methanol- $\mathrm{d}_{6}$. A delay time $(d l)$ of $60 \mathrm{~s}$ was applied in the NMR pulse sequence, to avoid saturation effects in the ${ }^{31} \mathrm{P}$ 15 NMR spectra, so that quantitative interpretation of the NMR spectra was possible. UV-VIS absorption spectra were recorded with a Varian Cary 5000 spectrophotometer, with a cuvette holder, which was heated to $80{ }^{\circ} \mathrm{C}$ by a circulating water bath. Quartz cuvettes with an optical path length of $0.1 \mathrm{~mm}$ were used 20 to record the spectra of the highly absorbing solutions.

\section{Extraction experiments}

Cobalt extraction between two mutually immiscible ionic liquids: Cobalt(II)chloride (5 g/L Co) was dissolved in 1-ethyl-3methylimidazolium chloride, $\left[\mathrm{C}_{2} \mathrm{mim}\right] \mathrm{Cl},(5.55 \mathrm{~g}, 5 \mathrm{~mL})$ at $95{ }^{\circ} \mathrm{C}$ 25 and trihexyl(tetradecyl)phosphonium bis(2,4,4-trimethylpentyl)phosphinate ( $\left[\mathrm{P}_{66614}\right]\left[\mathrm{R}_{2} \mathrm{POO}\right]$ with $\mathrm{R}=2,4,4$-tri(methylpentyl) (5 $\mathrm{mL}$ ) was used as extraction phase. The mixture of the two ionic liquids was stirred for 10 minutes at $95{ }^{\circ} \mathrm{C}$ and the metal content in both phases was analyzed after centrifugation $(3000 \mathrm{rpm}, 5$ $30 \mathrm{~min})$.

Extraction between two mutually immiscible ionic liquids from solution containing both cobalt and nickel:

$\mathrm{CoCl}_{2}$ and $\mathrm{NiCl}_{2}$ (both with a metal concentration of $5 \mathrm{~g} \mathrm{~L}^{-1}$ ) were dissolved in $\left[\mathrm{C}_{2} \operatorname{mim}\right] \mathrm{Cl}(5.55 \mathrm{~g}, 5 \mathrm{~mL})$ at $95{ }^{\circ} \mathrm{C}$. and 35 trihexyl(tetradecyl)phosphonium $\quad$ bis(2,4,4-trimethylpentyl)phosphinate, $\left[\mathrm{P}_{66614}\right]\left[\mathrm{R}_{2} \mathrm{POO}\right](5 \mathrm{~mL})$ was used as extraction phase. The extraction was stirred for 10 minutes at $95{ }^{\circ} \mathrm{C}$ and the metal content in both phases was analyzed after centrifugation (3000 rpm, $5 \mathrm{~min}$ ).

${ }_{40}$ Washing of the extraction phase:

the cobalt-loaded extraction phase $(5 \mathrm{~mL})$ was washed with water $(5 \mathrm{~mL})$ and stirred at $50{ }^{\circ} \mathrm{C}$ for 10 minutes. After washing, the phases were centrifuged (3000 rpm, $10 \mathrm{~min}$.) and the water phase was analyzed for its metal content.

${ }_{45}$ Stripping of cobalt from the extraction phase: After extraction, cobalt was stripped from the $\left[\mathrm{P}_{66614}\right]\left[\mathrm{R}_{2} \mathrm{POO}\right]$ phase with a $2 \mathrm{M}$ aqueous sulfuric acid solution. A volume ratio of 1:1 was used and the phases were stirred for 5 minutes at $50{ }^{\circ} \mathrm{C}$. The metal content in both phases was analyzed after centrifugation (3000 $50 \mathrm{rpm}, 5 \mathrm{~min})$.

Recovery of the extraction phase: The extraction phase $\left[\mathrm{P}_{66614}\right]\left[\mathrm{R}_{2} \mathrm{POO}\right]$ was regenerated after stripping by washing with an ammonia solution $(2 \mathrm{M})$. A volume ratio of $1: 1$ was used and the phases were stirred for 5 minutes at $50{ }^{\circ} \mathrm{C}$. The metal content 55 in both phases was analyzed after centrifugation (3000 rpm, 5 $\min )$.

\section{Distribution coefficients and separation factor}

The distribution ratios for cobalt, $\mathrm{D}_{\mathrm{Co}}$, were calculated for all 60 experiments, as follows:

$$
\mathrm{D}_{\mathrm{Co}}=\frac{[\mathrm{Co}]_{\mathrm{phos}}}{[\mathrm{Co}]_{\mathrm{im}}}=\frac{[\mathrm{Co}]_{0}-[\mathrm{Co}]_{\mathrm{im}}}{[\mathrm{Co}]_{\mathrm{im}}}
$$

where $[\mathrm{Co}]_{0}$ is the initial cobalt concentration in the $\left[\mathrm{C}_{2} \mathrm{mim}\right] \mathrm{Cl}$ phase before extraction, $[\mathrm{Co}]_{\mathrm{im}}$ is the cobalt concentration in the $\left[\mathrm{C}_{2} \mathrm{mim}\right] \mathrm{Cl}$ phase after the extraction, and $[\mathrm{Co}]_{\text {phos }}$ is the cobalt 65 concentration in $\left[\mathrm{P}_{66614}\right]\left[\mathrm{R}_{2} \mathrm{POO}\right]$ after extraction. Distribution ratios for nickel, $D_{\mathrm{Ni}}$, were calculated using the following equation:

$$
\mathrm{D}_{\mathrm{Ni}}=\frac{[\mathrm{Ni}]_{\mathrm{phos}}}{[\mathrm{Ni}]_{\mathrm{im}}}=\frac{[\mathrm{Ni}]_{\mathrm{phos}}}{[\mathrm{Ni}]_{0}-[\mathrm{Ni}]_{\mathrm{phos}}}
$$

where $[\mathrm{Ni}]_{0}$ is the initial cobalt concentration in the $\left[\mathrm{C}_{2} \mathrm{mim}\right] \mathrm{Cl}$ 70 phase before extraction, $[\mathrm{Ni}]_{\text {phos }}$ is the nickel concentration in the $\left[\mathrm{P}_{66614}\right]\left[\mathrm{R}_{2} \mathrm{POO}\right]$ ionic liquid after extraction, and $[\mathrm{Ni}]_{\mathrm{im}}$ is the nickel concentration in $\left[\mathrm{C}_{2} \mathrm{mim}\right] \mathrm{Cl}$ after extraction. The efficiency of separation of cobalt from nickel is described by the separation factor:

75

$$
\alpha_{\mathrm{Ni}}^{\mathrm{Co}}=\frac{\mathrm{D}_{\mathrm{Co}}}{\mathrm{D}_{\mathrm{Ni}}}
$$

\section{Results and Discussion}

\section{Selection of a suitable pair of ionic liquids}

Earlier work has shown that mixtures of some hydrophilic and some specific hydrophobic ionic liquids gave rise to two phases, 80 in particular when there are large structure differences in either the cation or the anion. ${ }^{22}$ Mutual immiscibility of the two ionic liquids is a necessary, but not sufficient condition. The hydrophilic ionic liquid, replacing the aqueous phase, needs to be an ionic liquid with coordination anions to enable the dissolution 85 of inorganic metal salts. The hydrophobic ionic liquid, acting as the organic phase, has to be able to dissolve the extracted metal complex. In principle, an ionic liquid with a dissolved extractant could be used, but we preferred to look for a non-fluorinated ionic liquid with coordinating anions. Moreover, although the 90 expression "mutually immiscible ionic liquids" is used, it must be realized that there is always a partial miscibility between any pair of ionic liquids. After screening of several ionic liquid combinations, the most promising system proved to be the one consisting of 1-ethyl-3-methylimidazolium chloride $\left(\left[\mathrm{C}_{2} \mathrm{mim}\right] \mathrm{Cl}\right)$ 95 and trihexyl(tetradecyl)phosphonium bis(2,4,4-trimethylpentyl)phosphinate, $\left[\mathrm{P}_{66614}\right]\left[\mathrm{R}_{2} \mathrm{POO}\right]$ or Cyphos ${ }^{\circledR}$ IL 104 (Figure 1). $\left[\mathrm{P}_{66614}\right]\left[\mathrm{R}_{2} \mathrm{POO}\right]$ has been explored by other authors as extractant for metals. ${ }^{30-32}$ Because the melting point of the ionic liquid $\left[\mathrm{C}_{2} \mathrm{mim}\right] \mathrm{Cl}$ is $77-79{ }^{\circ} \mathrm{C}$, the extraction studies needed to be 100 performed at elevated temperatures. 


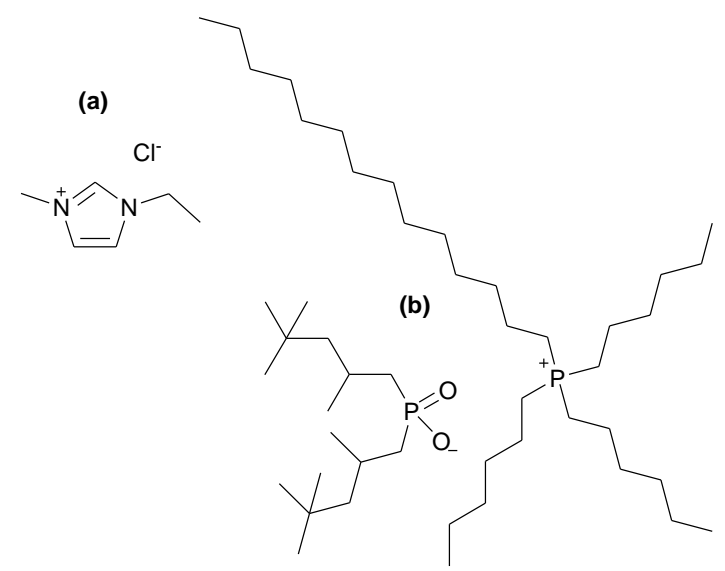

Figure 1: Chemical structures of (a) 1-ethyl-3-methylimidazolium chloride, $\left[\mathrm{C}_{2} \mathrm{mim}\right] \mathrm{Cl}$, and (b) trihexyl(tetradecyl)phosphonium bis $(2,4,4-$ trimethylpentyl)phosphinate, $\left[\mathrm{P}_{66614}\right]\left[\mathrm{R}_{2} \mathrm{POO}\right]$.

\section{Metal extraction}

The results for the extraction experiments are shown in Table 1. To be sure that the equilibrium condition was reached, the distribution ratio of an extraction with a stirring time of 10 10 minutes was compared with the distribution ratio of an extraction with a stirring time of 2 hours. For both stirring times, the distribution ratios for cobalt were identical, meaning that the extraction equilibrium was reached within 10 minutes Therefore, a stirring time of 10 minutes was used for all further extraction 15 experiments. A distribution ratio of $44.0( \pm 0.4)$ was found for the distribution of cobalt between the two mutually immiscible ionic liquids, for a solution with only $\mathrm{CoCl}_{2}$ present. Under the same condition, nickel is hardly extracted to the $\left[\mathrm{P}_{66614}\right]\left[\mathrm{R}_{2} \mathrm{POO}\right]$ phase $\left(\mathrm{D}_{\mathrm{Ni}}=0.06( \pm 0.008)\right)$. The extraction experiments showed a 20 selectivity of cobalt. A separation factor between cobalt and nickel of 200 was obtained. In Figure 2, the layering of the two mutually immiscible ionic liquids $\left[\mathrm{C}_{2} \mathrm{mim}\right] \mathrm{Cl}$ and $\left[\mathrm{P}_{66614}\right]\left[\mathrm{R}_{2} \mathrm{POO}\right]$ on top of each other and the distribution of $\mathrm{CoCl}_{2}$ and $\mathrm{NiCl}_{2}$ between them, is shown.

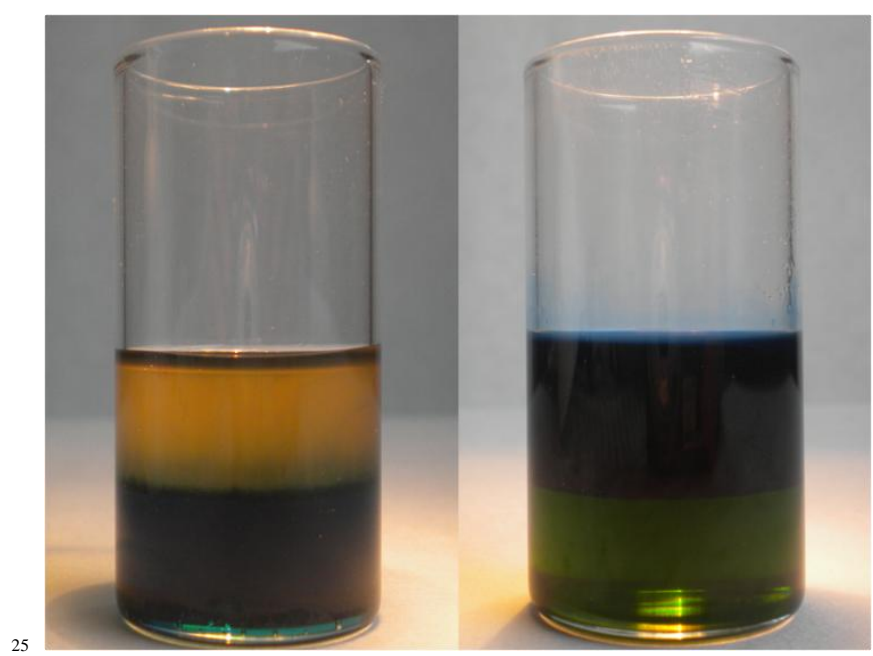

Figure 2: Sample showing the ionic liquid $\left[\mathrm{P}_{66614}\right]\left[\mathrm{R}_{2} \mathrm{POO}\right]$ layered on top of the ionic liquid $\left[\mathrm{C}_{2} \mathrm{mim}\right] \mathrm{Cl}$, before (left) and after (right) cobalt(II)extraction.
30 Table 1: Summary of the analysis results for the distribution of cobalt and nickel between the ionic liquids $\left[\mathrm{C}_{2} \mathrm{mim}\right] \mathrm{Cl}$ and $\left[\mathrm{P}_{66614}\right]\left[\mathrm{R}_{2} \mathrm{POO}\right]$ at 95 ${ }^{\circ} \mathrm{C}$, calculated for cobalt and nickel present in two different solutions (column A), and for cobalt and nickel present in the same solution (column B).

\begin{tabular}{ccc}
\hline Extraction parameters $^{\mathrm{a}}$ & $\mathrm{A}$ & $\mathrm{B}$ \\
{$[\mathrm{Co}]_{\mathrm{im}}(\mathrm{ppm})$} & $110( \pm 1)$ & $318( \pm 14)$ \\
{$[\mathrm{Ni}]_{\text {phos }}(\mathrm{ppm})$} & $283( \pm 35)$ & $332( \pm 4)$ \\
$\mathrm{D}_{\mathrm{Co}}$ & $44.0( \pm 0.4)$ & $14.7( \pm 0.7)$ \\
$\mathrm{D}_{\mathrm{Ni}}$ & $0.060( \pm 0.008)$ & $0.071( \pm 0.001)$ \\
$\mathrm{SF}_{\mathrm{Co}-\mathrm{Ni}}$ & $733( \pm 104)$ & $207( \pm 12)$
\end{tabular}

${ }_{35}{ }^{a}[\mathrm{Co}]_{\text {im }}$ : cobalt concentration in $\left[\mathrm{C}_{2} \mathrm{mim}\right] \mathrm{Cl}$ after extraction, $[\mathrm{Ni}]_{\text {phos }}$ : nickel concentration in $\left[\mathrm{P}_{66614}\right]\left[\mathrm{R}_{2} \mathrm{POO}\right]$ after extraction; $\mathrm{D}_{\mathrm{Co}}$ : distribution ratio for cobalt; $\mathrm{D}_{\mathrm{Ni}}$ : distribution ratio for nickel; $\mathrm{SF}_{\mathrm{Co}-\mathrm{Ni}}$ : separation factor for the cobalt-nickel separation.

${ }_{40}$ Comparing the separation factors calculated for the extraction experiment in which cobalt and nickel are present in two different solutions with the one in which both cobalt and nickel are present in the same solution (Table 1) shows that the separation factor is about 3.5 times lower in the latter case. This decrease in 45 separation factor is ascribed to the decrease in cobalt extraction, caused by a competition effect between cobalt and nickel to bind to the phosphinate ligands (vide infra).

To elucidate the extraction mechanism, the absorption spectra of cobalt(II) chloride dissolved in the $\left[\mathrm{C}_{2} \mathrm{mim}\right] \mathrm{Cl}$ ionic phase were 50 compared with that of the extracted cobalt(II) complex in the ionic liquid $\left[\mathrm{P}_{66614}\right]\left[\mathrm{R}_{2} \mathrm{POO}\right]$ (Figure 3 ). The absorption spectrum of $\mathrm{CoCl}_{2}$ in $\left[\mathrm{C}_{2} \mathrm{mim}\right] \mathrm{Cl}$ shows the typical spectrum of the tetrachlorocobaltate(II) complex, $\left[\mathrm{CoCl}_{4}\right]^{2-32,33}$ The absorption spectrum of cobalt in $\left[\mathrm{P}_{66614}\right]\left[\mathrm{R}_{2} \mathrm{POO}\right]$ is totally different, which 55 excludes the extraction of cobalt(II) as an anionic tetra(chloro)cobaltate species. The absorption spectrum is similar to those reported in the literature for $\mathrm{Co}\left(\mathrm{R}_{2} \mathrm{POO}\right)_{2},{ }^{31,34}$ indicating that cobalt(II) is present in $\left[\mathrm{P}_{66614}\right]\left[\mathrm{R}_{2} \mathrm{POO}\right]$ as the tetrahedral $\mathrm{Co}\left(\mathrm{R}_{2} \mathrm{POO}\right)_{2}$ complex. The following extraction mechanism is 60 proposed:

$\left[\mathrm{C}_{2} \mathrm{mim}\right]_{2}\left[\mathrm{CoCl}_{4}\right]+2\left[\mathrm{P}_{66614}\right]\left[\mathrm{R}_{2} \mathrm{POO}\right] \rightarrow 2\left[\mathrm{C}_{2} \mathrm{mim}\right] \mathrm{Cl}+2$

$\left[\mathrm{P}_{66614}\right] \mathrm{Cl}+\mathrm{Co}\left(\mathrm{R}_{2} \mathrm{POO}\right)_{2}$

In $\left[\mathrm{C}_{2} \mathrm{mim}\right] \mathrm{Cl}$, cobalt(II) is present as the $\left[\mathrm{CoCl}_{4}\right]^{2-}$ species. Upon mixing with $\left[\mathrm{P}_{66614}\right]\left[\mathrm{R}_{2} \mathrm{POO}\right]$, chloride ligands are replaced by ${ }_{65}$ phosphinate ligands, which have a high affinity for cobalt(II), and the $\left[\mathrm{Co}\left(\mathrm{R}_{2} \mathrm{POO}\right)_{2}\right]$ species is formed. Due to the large structural similarity of this complex with the hydrophobic ionic liquid $\left[\mathrm{P}_{66614}\right]\left[\mathrm{R}_{2} \mathrm{POO}\right]$ it will prefer this phase, resulting in an extraction of cobalt from the $\left[\mathrm{C}_{2} \mathrm{mim}\right] \mathrm{Cl}$ phase to the $70\left[\mathrm{P}_{66614}\right]\left[\mathrm{R}_{2} \mathrm{POO}\right]$ phase. The absorption spectrum of $\mathrm{NiCl}_{2}$ dissolved in $\left[\mathrm{C}_{2} \mathrm{mim}\right] \mathrm{Cl}$ indicates that the $\left[\mathrm{NiCl}_{4}\right]^{2-}$ species is present (Figure 3). ${ }^{32,33}$ After mixing of the nickel-containing $\left[\mathrm{C}_{2} \mathrm{mim}\right] \mathrm{Cl}$ with $\left[\mathrm{P}_{66614}\right]\left[\mathrm{R}_{2} \mathrm{POO}\right]$, the color of the $\left[\mathrm{C}_{2} \mathrm{mim}\right] \mathrm{Cl}$ phase switched from blue to pale yellow. The corresponding 75 absorption spectrum with an absorption maximum at $381 \mathrm{~nm}$ is typical one that is expected for an octahedral nickel complex. It is assumed that a mixed chloro-phosphinate nickel(II) complexes octahedral species of the type $\left[\mathrm{NiCl}_{\mathrm{x}}\left(\mathrm{R}_{2} \mathrm{POO}\right)_{\mathrm{y}}\right]^{(2-\mathrm{x}-\mathrm{y})}$ are formed, which cannot be extacted due to their polar character. The 80 formation of the mixed complexes implicates the loss of phosphinate ligands to the $\left[\mathrm{C}_{2} \mathrm{mim}\right] \mathrm{Cl}$ phase. 


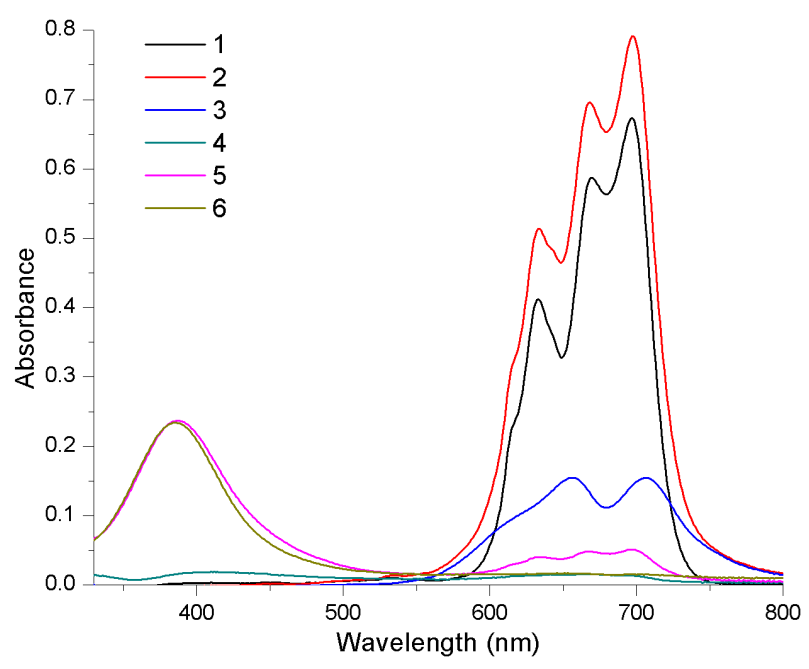

Figure 3: Absorption spectrum of $\mathrm{CoCl}_{2}$ and $\mathrm{NiCl}_{2}$ dissolved in the ionic liquid $\left[\mathrm{C}_{2} \mathrm{mim}\right] \mathrm{Cl}$ at $80^{\circ} \mathrm{C}$ (optical path length of $0.1 \mathrm{~mm}$ ), showing the presence of the $\left[\mathrm{CoCl}_{4}\right]^{2-}$ and the $\left[\mathrm{NiCl}_{4}\right]^{2-}$ anions and further of the octahedral nickel species $\left[\mathrm{NiCl}_{x} \mathrm{R}_{2} \mathrm{POO}_{y}\right]^{2-x-y}$ after extraction. With spectrum 1 corresponding to $\mathrm{CoCl}_{2}$ in $\left[\mathrm{C}_{2} \mathrm{mim}\right] \mathrm{Cl}$ before extraction; 2 to $\mathrm{CoCl}_{2}$ and $\mathrm{NiCl}_{2}$ in $\left[\mathrm{C}_{2} \mathrm{mim}\right] \mathrm{Cl}$ before extraction; 3 to $\mathrm{NiCl}_{2}$ in $\left[\mathrm{C}_{2} \mathrm{mim}\right] \mathrm{Cl}$ before extraction; 4 to cobalt in $\left[\mathrm{C}_{2} \mathrm{mim}\right] \mathrm{Cl}$ after extraction; 5 to cobalt and nickel in $\left[\mathrm{C}_{2} \mathrm{mim}\right] \mathrm{Cl}$ after extraction; and 6 to nickel in $\left[\mathrm{C}_{2} \mathrm{mim}\right] \mathrm{Cl}$

10 after extraction.

\section{Influence of temperature on distribution coefficient}

When the distribution ratio of cobalt was determined as a function of temperature between 95 and $140{ }^{\circ} \mathrm{C}$, a linear decrease of the distribution ratio with temperatures was observed (Figure $154)$.

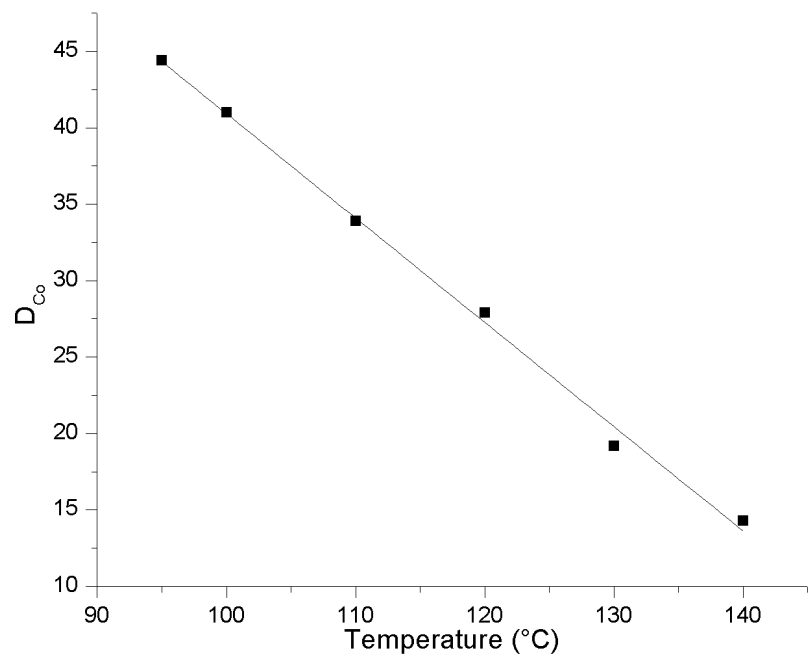

Fig 4: Distribution ratio for cobalt(II) as a function of temperature.

This behaviour can be explained by an increased solubility of both the phosphinate anion and the cobalt(II) phosphinate 20 complex in the ionic liquid $\left[\mathrm{C}_{2} \mathrm{mim}\right] \mathrm{Cl}$ with temperature. The solubility of $\left[\mathrm{R}_{2} \mathrm{POO}\right]^{-}$in $\left[\mathrm{C}_{2} \mathrm{mim}\right] \mathrm{Cl}$ was quantified at $140{ }^{\circ} \mathrm{C}$, by ${ }^{1} \mathrm{H}$ NMR measurement after bringing the two ionic liquids in contact by stirring their mixture for 10 minutes (see supporting information). An increase in the phosphinate concentration of 25 about $2000( \pm 120)$ ppm was observed, compared to the solubility at $95{ }^{\circ} \mathrm{C}$, which was about $1000 \mathrm{ppm}$. Because both the phosphinate and cobalt concentration are increasing with temperature in the $\left[\mathrm{C}_{2} \mathrm{mim}\right] \mathrm{Cl}$ phase after extraction, there will certainly be a correlation between these observation. To verify 30 the influence of phosphinate ligand on the cobalt extraction, absorption spectra were measured of the $\left[\mathrm{C}_{2} \mathrm{mim}\right] \mathrm{Cl}$ phase after extraction, both at $95{ }^{\circ} \mathrm{C}$ and $140{ }^{\circ} \mathrm{C}$ (Figure 5). A weak broad absorption band, with absorption maxima at 667 and $640 \mathrm{~nm}$ is observed. This band is laying in between the absorption bands of $35\left[\mathrm{CoCl}_{4}\right]^{2-}(697,670,633 \mathrm{~nm})$ and $\mathrm{Co}\left(\mathrm{R}_{2} \mathrm{POO}\right)_{2}$ at $(640,590$ and $563 \mathrm{~nm}$ ) (see supporting information), suggesting that both species are present in solution at certain ratio. The increase of light absorption at $140{ }^{\circ} \mathrm{C}$ compared to the spectra measured at 95 ${ }^{\circ} \mathrm{C}$, also suggests the concentration increase of the phosphinate 40 anion directly bonded to cobalt in the $\left[\mathrm{C}_{2} \mathrm{mim}\right] \mathrm{Cl}$ phase and is a direct evidence that the phosphinate concentration present in $\left[\mathrm{C}_{2} \mathrm{mim}\right] \mathrm{Cl}$ influences the cobalt extraction behavior. Upon extraction, the cobalt(II) phosphinate species are distributed over the two phases and this ratio is temperature dependent. This 45 provides a logical explanation for the differences in distribution ratios at different temperatures.

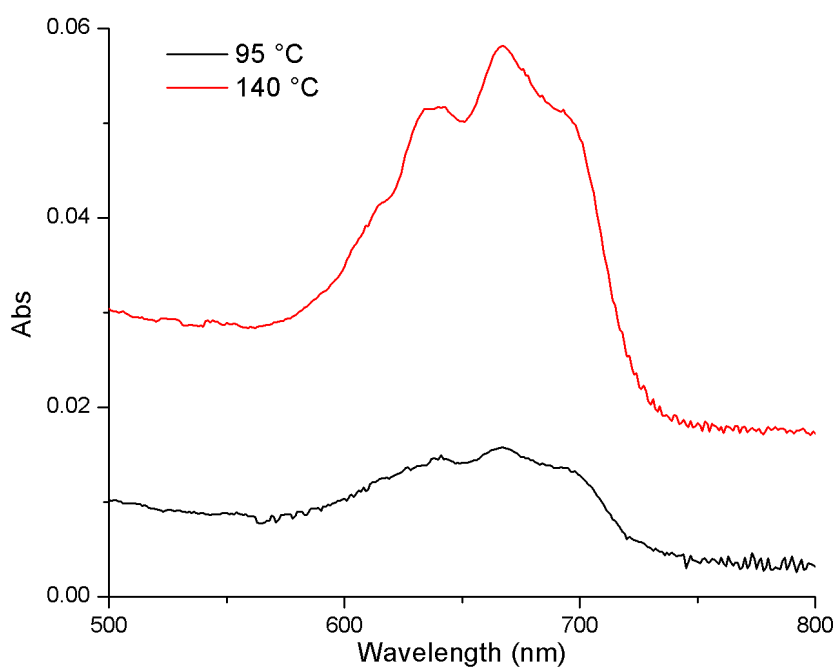

Figure 5 Absorption spectra of the $\left[\mathrm{C}_{2} \mathrm{mim}\right] \mathrm{Cl}$ phase after extraction at 95 and $140^{\circ} \mathrm{C}$.

\section{${ }_{50}$ Quantification of the mutual solubility}

To quantify the solubility of $\left[\mathrm{C}_{2} \mathrm{mim}\right] \mathrm{Cl}$ in $\left[\mathrm{P}_{66614}\right]\left[\mathrm{R}_{2} \mathrm{POO}\right]$, a ${ }^{1} \mathrm{H}$ NMR spectrum was recorded after bringing the two ionic liquids in contact by stirring their mixture for 10 minutes at $95{ }^{\circ} \mathrm{C}$. These conditions resemble those of the solvent extraction experiments 55 (vide supra). The presence of $\left[\mathrm{C}_{2} \mathrm{mim}\right] \mathrm{Cl}$ in the $\left[\mathrm{P}_{66614}\right]\left[\mathrm{R}_{2} \mathrm{POO}\right]$ phase was quantified by integrating characteristic resonances in the NMR spectrum, corresponding to one of the two ionic liquid molecules (see supporting information). The peak at $\delta=11.7$ ppm, originating from the hydrogen atom at $\mathrm{C} 2$ position of the 60 imidazolium ring, was integrated and related to the integration of the peak at $\delta=2.5 \mathrm{ppm}$, originating from the eight hydrogen atoms at $\mathrm{C} 1$ position of the phosphonium cation. A solubility of 9.2 wt. \% (or $31 \mathrm{~mol} \%$ ) of $\left[\mathrm{C}_{2} \mathrm{mim}\right] \mathrm{Cl}$ in $\left[\mathrm{P}_{66614}\right]\left[\mathrm{R}_{2} \mathrm{POO}\right]$ was determined from the ratio of the integrated peaks. The same ${ }_{65}$ procedure was applied to measure the solubility of the $\left[\mathrm{P}_{66614}\right]^{+}$ cation in $\left[\mathrm{C}_{2} \mathrm{mim}\right] \mathrm{Cl}$. The signals were too weak for a reliable integration. Although an accurate determination of the solubility 
of the phosphonium cation $\left[\mathrm{P}_{66614}\right]^{+}$in $\left[\mathrm{C}_{2} \mathrm{mim}\right] \mathrm{Cl}$ was not possible, it can be concluded that the solubility is very low. However, only measuring the solubility of the cation is not sufficient, since anions can exchange as well (phosphinate anions 5 then replace chlorides). The solubility of the phosphinate anions can be measured by integration of the resonances in the ${ }^{1} \mathrm{H}$ NMR spectrum at $\delta=0.89$. A solubility of about $1000 \mathrm{ppm}$ was found. Since the process is used for the extraction of cobalt, which has a high affinity for phosphinate ligands, the phosphinate 10 concentration in $\left[\mathrm{C}_{2} \mathrm{mim}\right] \mathrm{Cl}$ is expected to be even lower, after mixing the phases.

\section{Further processing steps}

Because the solubility of $\left[\mathrm{C}_{2} \mathrm{mim}\right] \mathrm{Cl}$ in $\left[\mathrm{P}_{66614}\right]\left[\mathrm{R}_{2} \mathrm{POO}\right]$ is about 159 wt.\% (vide supra), $\left[\mathrm{C}_{2} \mathrm{mim}\right] \mathrm{Cl}$ needs to be recovered from the extraction phase to avoid unacceptable losses of ionic liquid. $\left[\mathrm{C}_{2} \mathrm{mim}\right] \mathrm{Cl}$ dissolved in $\left[\mathrm{P}_{66614}\right]\left[\mathrm{R}_{2} \mathrm{POO}\right]$ could be selectively removed from the cobalt-loaded $\left[\mathrm{P}_{66614}\right]\left[\mathrm{R}_{2} \mathrm{POO}\right]$ phase by washing with a neutral water solution, because $\left[\mathrm{C}_{2} \mathrm{mim}\right] \mathrm{Cl}$ is 20 water soluble and the other components, including the cobalt(II) phosphinate complex, are not, since this ionic liquid is immiscible with water. The $\left[\mathrm{C}_{2} \mathrm{mim}\right] \mathrm{Cl}$ content in the $\left[\mathrm{P}_{66614}\right]\left[\mathrm{R}_{2} \mathrm{POO}\right]$ phase after the washing step, was only 0.12 wt.\% (verified by ${ }^{1} \mathrm{H}$ NMR, see supporting information).

25 . Only $7 \mathrm{ppm}$ of cobalt was detected in the aqueous washing solution. $\left[\mathrm{C}_{2} \mathrm{mim}\right] \mathrm{Cl}$ could be recycled from the washing solution by evaporation of water. Cobalt was stripped from the $\left[\mathrm{P}_{66614}\right]\left[\mathrm{R}_{2} \mathrm{POO}\right]$ ionic liquid phase by an aqueous $2 \mathrm{M}$ sulfuric acid solution, by which the bonded cobalt ions will be exchanged 30 by protons. In one single stripping step, the cobalt content in the
$\left[\mathrm{P}_{66614}\right]\left[\mathrm{R}_{2} \mathrm{POO}\right]$ extraction phase was reduced to $127 \mathrm{ppm}$, showing that virtually all of the extracted cobalt could be recovered by stripping to the aqueous phase. Because phosphinic acid is formed during the stripping step (5), a deprotonation step 35 is necessary to regenerate the phosphonium phosphinate ionic liquid (6):

$$
\begin{aligned}
& {\left[\mathrm{P}_{66614}\right]\left[\mathrm{R}_{2} \mathrm{POO}\right]+\mathrm{H}_{2} \mathrm{SO}_{4} \rightarrow\left[\mathrm{P}_{66614}\right]\left[\mathrm{HSO}_{4}\right]+\mathrm{R}_{2} \mathrm{POOH}} \\
& {\left[\mathrm{P}_{66614}\right]\left[\mathrm{HSO}_{4}\right]+\mathrm{R}_{2} \mathrm{POOH}+2 \mathrm{NH}_{3} \rightarrow\left[\mathrm{P}_{66614}\right]\left[\mathrm{R}_{2} \mathrm{POO}\right]+} \\
& \left(\mathrm{NH}_{4}\right)_{2}\left(\mathrm{SO}_{4}\right)
\end{aligned}
$$

40 This was achieved by washing the extraction phase which is immiscible with water, after stripping with a $2 \mathrm{M}$ aqueous ammonia solution. After recovery, $\left[\mathrm{P}_{66614}\right]\left[\mathrm{R}_{2} \mathrm{POO}\right]$ contained 14.3 wt.\% of water, which had to be removed by evaporation before reuse of the ionic liquid in a next extraction experiment 45 with two immiscible ionic liquids. To prove that a $1: 1$ phosponium-to-phosphinate ratio was retained in the ionic liquid $\left[\mathrm{P}_{66614}\right]\left[\mathrm{R}_{2} \mathrm{POO}\right]$, the extraction, stripping and regeneration procedure was repeated in the absence of cobalt (to avoid paramagnetic impurities), and ${ }^{31} \mathrm{P}$ NMR spectra were recorded 50 (see supporting information). A 1:1 ratio was found for the integrations of the peaks at $\delta=38.11$ and $\delta=43.63$, corresponding to the trihexyltetradecyl-phosphonium cation and bis(2,4,4-trimethylpentyl)phosphinate anion, respectively. It can be concluded that no components of the ionic liquid $55\left[\mathrm{P}_{66614}\right]\left[\mathrm{R}_{2} \mathrm{POO}\right]$ are lost during the processing procedure. All processing steps used for the cobalt-nickel separation are summarized in the flow chart shown in Figure 6.

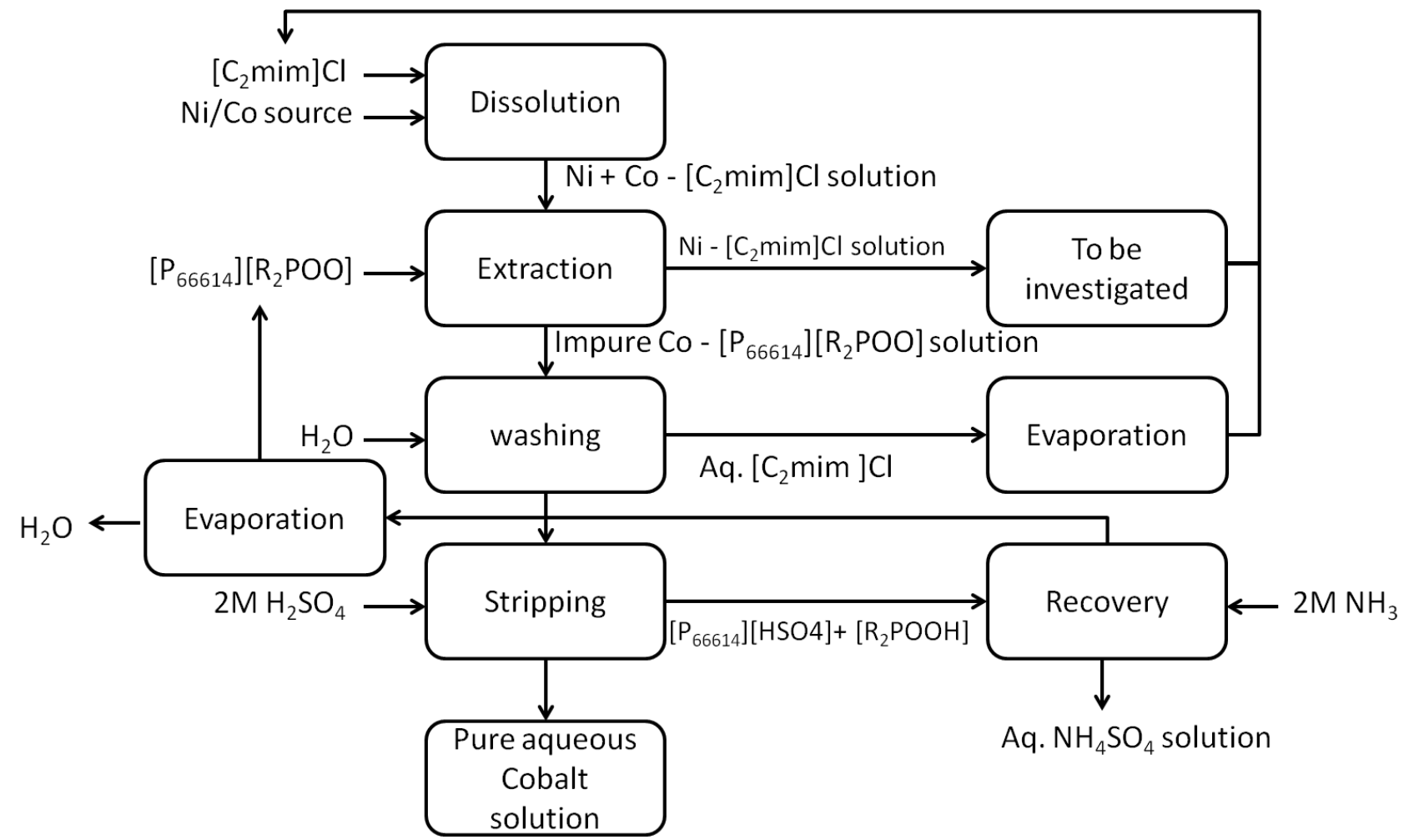

Figure 6: Flow chart for cobalt-nickel separation using mutually immiscible ionic liquids. 


\section{Conclusion}

For the first time the separation of metals by solvent extraction using two mutually immiscible ionic liquids has been shown. Cobalt was extracted from the ionic liquid 1-ethyl-35 methylimidazolium chloride to the ionic liquid trihexyl(tetradecyl)phosphonium bis-(2,4,4-trimethylpentyl)phosphinate. A distribution ratio of 44 was obtained. Cobalt could be selectively separated from nickel, with a separation factor of 205. Stripping of cobalt from the hydrophobic ${ }_{10}$ phosphonium ionic liquid phase, followed by regeneration of the ionic liquid, was demonstrated, showing the potential of the method for use in a continuous extraction process. By replacement of the aqueous phase in solvent extraction by an ionic liquid phase, one can no longer speak about a 15 hydrometallurgical process. The term to use is "ionometallurgy"36 or "solvometallurgy", rather than hydrometallurgy.

\section{Acknowledgements}

This research was supported by the Flemish Institute for the Promotion of Innovation by Science and Technology (IWT 20 Vlaanderen) via a Baekeland PhD fellowship to Sil Wellens (IWT 090272) and by Umicore Group Research. Support by IoLiTec (Heilbronn, Germany), Cytec (Canada) and KU Leuven (research project GOA 13/008) is also gratefully acknowledged.

\section{Notes and references}

${ }_{25}{ }^{a}$ KU Leuven-University of Leuven, Department of Chemistry, Celestijnenlaan 200F, P.O. Box 2404, B-3001 Heverlee (Belgium) E-mail: Koen.Binnemans@chem.kuleuven.be

${ }^{b}$ Umicore, Group Research \& Development, Competence Area Recycling and Extraction Technologies, Kasteelstraat 7, B-2250 Olen (Belgium).

$30 \dagger$ Electronic Supplementary Information (ESI) available: $\left[{ }^{1} \mathrm{H}\right.$ NMR, ${ }^{31} \mathrm{P}$ NMR and UV-VIS absorption spectra]. See DOI: 10.1039/b000000x/

1. J. Rydberg, M. Cox, C. Musikas, and G. R. Choppin, in Solvent Extraction: Principles and Practice, Marcel Dekker, Inc., New York, second edition ed., 2004.

35 2. J. G. Huddleston, H. D. Willauer, R. P. Swatloski, A. E. Visser, and R. D. Rogers, Chem. Commun., 1998, 1765.

3. A. E. Visser, R. P. Swatloski, S. T. Griffin, D. H. Hartman, and R. D. Rogers, Sep. Sci. Technol., 2001, 36, 785.

4. M. Zhang, V. Kamavaram, and R. G. Reddy, Miner. Metall. Proc., 2006, 23, 177

5. M. L. Dietz, Sep. Sci. Technol., 2006, 41, 2047.

6. N. Hirayama, Solvent. Extract. Res. Dev., 2011, 18, 1.

7. F. Kubota, Y. Baba, and M. Goto, Solvent. Extract. Res. Dev., 2012, 19, 17.

45 8. A. Stojanovic and B. K. Keppler, Sep. Sci. Technol., 2012, 47, 189. 9. P. R. V. Rao, K. A. Venkatesan, A. Rout, T. G. Srinivasan, and K. Nagarajan, Sep. Sci. Technol., 2012, 47, 204.
10. N. V. Plechkova and K. R. Seddon, Chem. Soc. Rev., 2008, 37, 123.

$50 \quad$ 11. T. Welton, Chem. Rev., 1999, 99, 2071.

12. P. Wasserscheid and W. Keim, Angew. Chem. Int. Ed., 2000, 39, 3772.

13. A. Stojanovic, D. Kogelnig, L. Fischer, S. Hann, M. Galanski, M. Groessl, R. Krachler, and B. K. Keppler, Aust. J. Chem., 2010, 63, 511.

14. A. Fortuny, M. T. Coll, and A. M. Sastre, Sep. Purif. Technol., 2012, 97, 137.

15. X. Q. Sun, Y. Ji, L. Guo, J. Chen, and D. Q. Li, Sep. Purif. Technol., 2011, 81, 25.

60 16. A. Cieszynska and M. Wisniewski, Sep. Purif. Technol., 2010, 73, 202.

17. S. Wellens, B. Thijs, and K. Binnemans, Green Chem., 2012, 14, 1657.

18. P. Nockemann, B. Thijs, S. Pittois, J. Thoen, C. Glorieux, K. Van Hecke, L. Van Meervelt, B. Kirchner, and K. Binnemans, J. Phys. Chem. B, 2006, 110, 20978.

19. A. P. Abbott, G. Frisch, J. Hartley, and K. S. Ryder, Green Chem., 2011, 13, 471.

20. J. A. Whitehead, G. A. Lawrance, and A. McCluskey, Green Chem., 2004, 6, 313.

21. J. A. Whitehead, J. Zhang, N. Pereira, A. McCluskey, and G. A. Lawrance, Hydrometallurgy, 2007, 88, 109.

22. A. Arce, M. J. Earle, S. P. Katdare, H. Rodriguez, and K. R. Seddon, Chem. Commun., 2006, 2548.

75 23. A. Arce, M. J. Earle, S. P. Katdare, H. Rodriguez, and K. R. Seddon, Fluid Phase Equilibr., 2007, 261, 427.

24. G. Annat, M. Forsyth, and D. R. Macfarlane, J. Phys. Chem. B, 2012, 116, 8251.

25. A. Arce, M. J. Earle, S. P. Katdare, H. Rodriguez, and K. R. Seddon, Phys. Chem. Chem. Phys., 2008, 10, 2538.

26. N. M. Isaac, P. R. Fields, and D. M. Gruen, J. Inorg. Nucl .Chem., 1961, 21, 152.

27. Y. Aratono and E. Akatsu, J. Inorg. Nucl. Chem., 1974, 36, 1141.

28. T. Mitsugashira, M. Kamoshida, Y. Suzuki, and I. Satoh, J.Alloys Compd., 1994, 213, 347.

29. Y. Liu, L. Zhu, X. Sun, J. Chen, and F. Luo, Ind. Eng. Chem. Res., 2009, 48, 7308.

30. A. Cieszynska and M. Wisniewski, Hydrometallurgy, 2012, 113, 79.

31. P. Rybka and M. Regel-Rosocka, Sep. Sci. Technol., 2012, 47, 1296.

32. L. E. Orgel, J. Chem. Phys., 1955, 23, 1004.

33. P. B. Hitchcock, K. R. Seddon, and T. Welton, J. Chem .Soc. Dalton, 1993, 2639. 
34. N. B. Devi, K. C. Nathsarma, and V. Chakravortty, Hydrometallurgy, 1994, 34, 331.

35. C. J. Bradaric, A. Downard, C. Kennedy, A. J. Robertson, and Y. H. Zhou, Green Chem., 2003, 5, 143.

$5 \quad 36$. A. Abbott, G. Frisch, S. Gurman, A. Hillman, J. Hartley, F.

Holyoak, and K. Ryder, Chem. Commun., 2011, 47, 10031. 